\title{
O Programa Reuni e os desafios para a formação profissional em Serviço Social
}

\author{
Kátia Regina de Souza Lima \\ Universidade Federal Fluminense (UFF)
}

\section{O Programa Reuni e os desafios para a formação profissional em Serviço Social}

Resumo: Este artigo analisa a implantação do Programa de Apoio ao Plano de Reestruturação e Expansão das Universidades Federais (Reuni), particularmente no que se refere à ampliação do número de vagas discentes ofertadas nos cursos de Serviço Social das universidades federais. Identifica o Reuni como uma expressão da política de expansão em curso no Brasil na primeira década do novo século. Ao final, o texto problematiza o significado político e pedagógico do referido Programa, seus impactos na intensificação do trabalho docente e na formação profissional em Serviço Social.

Palavras-chave: Reuni. Universidade federal. Trabalho docente. Formação profissional. Serviço Social.

\section{The Reuni Program and Challenges for Professional Education in Social Work}

Abstract: This article analyzes the implementation of the Program for Support to Plans for the Restructuring and Expansion of Federal Universities (Reuni), particularly concerning the expansion of the number of openings for students in the schools of Social Work at federal universities. It identifies Reuni as an expression of the expansion policy underway in Brazil in the first decade of the new century. The text analyzes the political and pedagogical significance of the program, it's impacts on the intensification of the work of teaching and on professional education in Social Work.

Keywords: Reuni. Federal university. Teaching. Professional education. Social Work. 


\section{Introdução}

O trabalho apresenta os resultados parciais das pesquisas que realizamos em uma universidade federal sediada no Rio de Janeiro sobre a expansão da educação superior e seus impactos no trabalho docente, especialmente, no período de implantação do Programa de Apoio ao Plano de Reestruturação e Expansão das Universidades Federais (Reuni, 2006/2010). Considera que o referido Programa está inscrito no conjunto de ações constitutivas da contrarreforma do Estado e da educação superior em curso no Brasil (LIMA, 2010, 2011) e que a certificação em larga escala e a intensificação do trabalho docente ${ }^{1}$ constituem duas faces centrais da referida política de expansão. Ambas reconfiguram profundamente as universidades públicas brasileiras, particularmente, as universidades federais, reduzidas, em parte, a instituições de "educação terciária", conforme noção elaborada e difundida pelo Banco Mundial (2002). Através deste importante deslocamento da concepção de educação superior para "educação terciária", o Banco Mundial reivindica o aprofundamento da diversificação das instituições de ensino superior e dos cursos, com ênfase no ensino de graduação, desvinculado da pesquisa e da produção crítica e criativa do conhecimento (BARRETO; LEHER, 2008; LIMA, 2011).

Uma importante referência desta política de expansão com ênfase no ensino de graduação é o Programa Reuni, apresentado através do Decreto Presidencial n. 6.096/2007, com os seguintes objetivos: aumentar o número de estudantes de graduação nas universidades federais; diversificar as modalidades dos cursos de graduação, através da flexibilização dos currículos, do ensino a distância, da criação dos cursos de curta duração, dos ciclos (básico e profissional) e/ou bacharelados interdisciplinares; incentivar a criação de um novo sistema de certificações; elevar a taxa de conclusão dos cursos de graduação para $90 \%$ e estimular a mobilidade estudantil entre as instituições de ensino (BRASIL, 2007).

Para cada universidade federal que aderisse a este "termo de pactuação de metas", ou seja, um "contrato de gestão" com o Ministério da Educação (MEC), o governo "prometia" um acréscimo de recursos limitado a $20 \%$ das despesas de custeio e pessoal. Uma análise cuidadosa do parágrafo terceiro dos artigos terceiro e sétimo do Decreto de criação do Reuni deixava claro em que termos ocorreria esta "expansão", pois o atendimento aos planos foi condicionado à capacidade orçamentária e operacional do Ministério da Educação (LIMA, 2010).

Os limites do orçamento da União para a expansão e reestruturação das universidades federais logo foram evidenciados. Em 27 de agosto de 2009, a página do Sindicato Nacional dos Docentes das Instituições de Ensino Superior (ANDES-SN, 2009) destacava a seguinte notícia:

Dinheiro do Reuni já acabou, diz ministro. Os R \$ 2,5 bilhões destinados a financiar os quatro anos de implementação do Programa de Reestruturação e Expansão das Universidades Federais (Reuni) já foram comprometidos nos dois primeiros anos do projeto e não há previsões de como o governo que tomará posse em 2010 arcará com a despesa oriunda desse crescimento desenfreado das universidades públicas, promovido pelo governo Lula.

A lógica imposta pelo Reuni - sua centralidade na expansão do ensino de graduação - constitui uma das expressões da precarização e da intensificação do trabalho docente; da certificação em larga escala e da quebra da indissociabilidade entre ensino, pesquisa e extensão na atualidade (LIMA, 2010, 2011a).

A precarização e a intensificação do trabalho docente referem-se a formas de trabalho inscritas no processo mais amplo de alterações estruturais no capitalismo.

Destacamos, com base em Antunes e Alves (2004), quatro eixos da intensificação estrutural do trabalho no contexto da mundialização financeira: a ampliação de formas mais desregulamentadas de trabalho, reduzindo o conjunto de trabalhadores estáveis com empregos formais e gerando, simultaneamente, o surgimento de trabalhadores terceirizados e subcontratados; a pressão exercida em relação aos trabalhadores contratados no sentido de submissão à intensificação da exploração em um contexto de desemprego estrutural; o uso das inovações tecnológicas, substituindo a força humana de trabalho e comprimindo o tempo/espaço da produção a favor do capital e a imposição de uma lógica empresarial/mercantil/produtivista ao trabalho e mesmo à totalidade da vida social.

É neste sentido, portanto, que se deve conceber o significado da intensificação do trabalho docente: o resultado da ação destrutiva do capital no contexto da sua mundialização e as particularidades deste processo em um país capitalista dependente, como o Brasil.

Apesar das análises críticas e ações políticas do movimento sindical organizado no Andes-SN e nos setores não governistas da Federação dos Sindicatos de Trabalhadores das Universidades Brasileiras (Fasubra) e do movimento estudantil de oposição à União Nacional dos Estudantes (UNE), o Reuni 
foi saudado pela Associação Nacional dos Dirigentes das Instituições Federais de Ensino Superior (Andifes) como uma das mais relevantes iniciativas da política de expansão do MEC.

Uma importante referência deste compartilhamento de concepções e ações pode ser encontrada no Relatório de Acompanhamento do Programa de Apoio a Planos de Reestruturação e Expansão - Reuni - elaborado e divulgado pela Andifes, em 2010, apresentando dados sobre a expansão das vagas discentes nas universidades federais.

\section{A ampliação de vagas discentes nos cursos de Serviço Social das universidades federais: os números da certificação em larga escala}

A expansão da educação superior está sendo realizada, conforme o Relatório, por meio do aumento do número de vagas discentes nos cursos de graduação já existentes, da criação de novos cursos e das ações que objetivam diminuir as taxas de evasão e as vagas ociosas (ANDIFES, 2010).

O documento apresenta o ano de 2006 (ano do Programa Expansão para o Interior, do Governo Federal) como referência dos dados sobre a ampliação da oferta de vagas discentes na graduação presencial.

Em 2006, eram ofertadas 122.003 vagas nos cursos de graduação presencial das universidades federais. Em 2010, foram ofertadas 199.282, demonstrando que houve um aumento de 77.279 vagas ou $63 \%$ no período de 2006 a 2010 (ANDIFES, 2010, p. 10).

A tabela 3 do referido documento, intitulada Trinta cursos com maior número de vagas ofertadas nos processos seletivos das IFES para 2010, apresenta os dados da evolução de vagas no período de 2006 a 2010. Uma análise detalhada dessa tabela revela que os cursos com maior número de vagas, no período de 2006 a 2010, são os seguintes: $1^{\circ}$ Tecnólogo com um aumento de 756,08\%; $2^{\circ}$ Serviço Social com 116,19\%; $3^{\circ}$ Ciências da Computação com 106,66\% e $4^{\circ}$ Nutrição com 102,34\%. O curso com menor oferta de vagas, no período acima indicado, foi o curso de Medicina com 19,07\% (ANDIFES, 2010, p. 13).

A identificação do curso de Serviço Social como um dos cursos com maior oferta de vagas discentes nas universidades federais estimula alguns questionamentos. Como está ocorrendo a política de expansão conduzida pelo Reuni e quais os seus impactos no trabalho docente e na formação profissional em Serviço Social? Quais são as universidades federais que apresentaram maior oferta de vagas discentes nos cursos de graduação em Serviço Social no período 2006-2010? A ampliação das vagas discentes corresponde à ampliação de vagas docentes ou expressa um mecanismo de intensificação do trabalho docente na atualidade?

Construímos como hipótese que a ampliação das vagas discentes, sem o aumento correspondente das vagas docentes, opera a redução dos cursos de Serviço Social a unidades de "educação terciária", quebrando a indissociabilidade ensino, pesquisa e extensão e, consequentemente, ameaçando o projeto de formação profissional, que foi construído historicamente pelas entidades nacionais representativas: a Associação Brasileira de Ensino e Pesquisa em Serviço Social (Abepss), a Executiva Nacional de Estudantes de Serviço Social (Enesso) e o Conselho Federal de Serviço Social (Cfess).

O estudo do Relatório elaborado pela Andifes (2010) nos dá algumas pistas de como a expansão está sendo realizada nas universidades federais, particularmente, nos cursos de Serviço Social. Os quadros a seguir apresentam os números da ampliação de vagas discentes nos cursos de graduação em Serviço Social por região, no período 2006-2010.

A análise do quadro 1, referente à Região Norte, demonstra que, nos anos de 2009 e 2010, ocorreu a maior oferta de vagas discentes, especialmente nos cursos noturnos.

Na Região Norte, o curso de Serviço Social da Universidade Federal de Tocantins (UFT) passou de 40 vagas discentes, ofertadas em 2007, para 80 vagas discentes no ano de 2010: o dobro da oferta. O mesmo mecanismo de ampliação pode ser identificado nos cursos de Serviço Social das universidades federais sediadas na Região Nordeste.

Na Região Nordeste, quadro 2, os cursos de Serviço Social também dobraram a oferta de vagas discentes. Na Universidade Federal da Paraíba (UFPB), a oferta era de 90 vagas em 2006 e, em 2010, este número aumentou para 180. Na Universidade Federal da Bahia (UFBA), o curso ofereceu 45 vagas em 2009 e 90 vagas em 2010, um aumento significativo em apenas um ano. Na Universidade Federal do Recôncavo da Bahia (UFRB), as vagas ofertadas quase triplicaram: de 40 vagas, em 2008, para 100 em 2010.

Na Região Centro-Oeste, quadro 3, dois mecanismos de expansão foram postos em ação: a ampliação do número de vagas discentes em um curso criado em período anterior ao Reuni e a criação de um curso novo de Serviço Social. 
Quadro 1 - Ampliação de vagas discentes nos cursos de graduação em Serviço Social da Região Norte no período 2006-2010

\begin{tabular}{|c|c|c|c|c|c|c|c|}
\hline \multirow{2}{*}{$\begin{array}{c}\text { Universidade } \\
\text { federal }\end{array}$} & \multirow[t]{2}{*}{ Cidade } & \multirow[t]{2}{*}{ Vagas por ano/turno } & \multicolumn{5}{|c|}{ Total por ano } \\
\hline & & & 2006 & 2007 & 2008 & 2009 & 2010 \\
\hline \multirow[b]{2}{*}{ UFAM } & Manaus & $\begin{array}{l}\text { 2006-2010: } 56 \text { vagas /diurno e } \\
\text { 2009-2010: } 42 \text { vagas/noturno }\end{array}$ & 56 & 56 & 56 & 98 & 98 \\
\hline & Parintins & 2007-2010: 50 vagas/diurno & 0 & 50 & 50 & 50 & 50 \\
\hline \multirow{2}{*}{ UFPA } & Belém & $\begin{array}{l}\text { 2006-2010: } 80 \text { vagas/diurno e } \\
40 \text { vagas/noturno }\end{array}$ & 120 & 120 & 120 & 120 & 120 \\
\hline & Breves & 2009-2010: 40 vagas/noturno & 0 & 0 & 0 & 40 & 40 \\
\hline UFT & Miracema & $\begin{array}{l}\text { 2007-2009: } 40 \text { vagas/noturno; } \\
\text { 2008 e 2009: } 40 \text { vagas/diurno e } \\
\text { 2010: } 80 \text { vagas/diurno }\end{array}$ & 0 & 40 & 80 & 80 & 80 \\
\hline
\end{tabular}

Fonte: Elaborado pela autora com base em Andifes (2010).

Quadro 2 - Ampliação de vagas discentes nos cursos de graduação em Serviço Social da Região Nordeste no período 2006-2010

\begin{tabular}{|c|c|c|c|c|c|c|c|}
\hline \multirow{2}{*}{$\begin{array}{l}\text { Universidade } \\
\text { federal }\end{array}$} & \multirow[t]{2}{*}{ Cidade } & \multirow[t]{2}{*}{ Vagas por ano/turno } & \multicolumn{5}{|c|}{ Total por ano } \\
\hline & & & 2006 & 2007 & 2008 & 2009 & 2010 \\
\hline \multirow{2}{*}{ UFAL } & Arapiraca & $\begin{array}{l}\text { 2006-2008: } 40 \text { vagas/diurno e } \\
\text { 2009-2010: } 50 \text { vagas/noturno }\end{array}$ & 40 & 40 & 40 & 50 & 50 \\
\hline & Maceió & $\begin{array}{l}\text { 2006-2010: } 70 \text { vagas/diurno e } \\
70 \text { vagas/noturno }\end{array}$ & 140 & 140 & 140 & 140 & 140 \\
\hline UFBA & Salvador & $\begin{array}{l}\text { 2009: } 45 \text { vagas/diurno e } \\
\text { 2010: } 90 \text { vagas/diurno }\end{array}$ & 0 & 0 & 0 & 45 & 90 \\
\hline UFCG & Sousa & 2010: $50 \mathrm{v}$,agas/diurno & 0 & 0 & 0 & 0 & 50 \\
\hline UFMA & São Luís & $\begin{array}{l}\text { 2006: } 60 \text { vagas/diurno e } \\
\text { 2007/2009: } 80 \text { vagas/diurno } \\
\text { (2010: sem dados no Relatório) }\end{array}$ & 60 & 80 & 80 & 80 & 0 \\
\hline UFPB & João Pessoa & $\begin{array}{l}\text { 2006/2008: } 45 \text { vagas/diurno e } \\
45 \text { vagas/noturno; } \\
\text { 2009/2010: } 90 \text { vagas/diurno e } \\
90 \text { vagas/noturno }\end{array}$ & 90 & 90 & 90 & 180 & 180 \\
\hline UFPE & Recife & 2006/2010: 120 vagas/diurno & 120 & 120 & 120 & 120 & 120 \\
\hline UFPI & Teresina & $\begin{array}{l}\text { 2006:45 vagas/diurno e } \\
\text { 2007/2010: } 50 \text { vagas/diurno }\end{array}$ & 45 & 50 & 50 & 50 & 50 \\
\hline UFRB & Cachoeira & $\begin{array}{l}\text { 2008: } 40 \text { vagas/diurno; } \\
\text { 2009: } 50 \text { vagas/diurno e } \\
\text { 2010: } 50 \text { vagas/diurno e } \\
50 \text { vagas/noturno }\end{array}$ & 0 & 0 & 40 & 50 & 100 \\
\hline UFRN & Natal & $\begin{array}{l}\text { 2006/2008: } 80 \text { vagas/diurno e } \\
\text { 2009/2010: } 94 \text { vagas/diurno }\end{array}$ & 80 & 80 & 80 & 94 & 94 \\
\hline UFS & São Cristovão & 2006/2010: 80 vagas/diurno & 80 & 80 & 80 & 80 & 80 \\
\hline
\end{tabular}

Fonte: Elaborado pela autora com base em Andifes (2010). 


\section{Quadro 3 - Ampliação de vagas discentes nos cursos de graduação em Serviço Social da Região Centro-Oeste no período 2006-2010}

\begin{tabular}{|c|c|c|c|c|c|c|c|}
\hline \multirow{2}{*}{$\begin{array}{l}\text { Universidade } \\
\text { federal }\end{array}$} & \multirow[t]{2}{*}{ Cidade } & \multirow[t]{2}{*}{ Vagas por ano/turno } & \multicolumn{5}{|c|}{ Total por ano } \\
\hline & & & 2006 & 2007 & 2008 & 2009 & 2010 \\
\hline UFG & Goiás & 2009/2010: 50 vagas/noturno & 0 & 0 & 0 & 50 & 50 \\
\hline UnB & Brasília & $\begin{array}{l}\text { 2006/2008: } 60 \text { vagas/diurno; } \\
\text { 2009: } 70 \text { vagas/diurno e } \\
\text { 2010: } 80 \text { vagas/diurno e } \\
80 \text { vagas/noturno }\end{array}$ & 60 & 60 & 60 & 70 & 160 \\
\hline
\end{tabular}

Fonte: Elaborado pela autora com base em Andifes (2010).

No Centro-Oeste, quadro 3, portanto, a universidade que mais ampliou o número de vagas foi a Universidade de Brasília (UnB): de 60 vagas, em 2006, para 160 em 2010.

$\mathrm{Na}$ Região Sul, encontramos certa estabilidade na oferta de vagas discentes e a criação de dois cursos novos, como evidencia o quadro 4.

Quadro 4 - Ampliação de vagas discentes nos cursos de graduação em Serviço Social da Região Sul no período 2006-2010

\begin{tabular}{|c|c|c|c|c|c|c|c|}
\hline \multirow{2}{*}{$\begin{array}{c}\text { Universidade } \\
\text { federal }\end{array}$} & \multirow[t]{2}{*}{ Cidade } & \multirow[t]{2}{*}{ Vagas por ano/turno } & \multicolumn{5}{|c|}{ Total por ano } \\
\hline & & & 2006 & 2007 & 2008 & 2009 & 2010 \\
\hline UFPR & Matinhos & $\begin{array}{l}\text { 2006/2009: } \\
30 \text { vagas/diurno }\end{array}$ & 30 & 30 & 30 & 30 & 0 \\
\hline UFRGS & Porto Alegre & 2010: 30 vagas/noturno & 0 & 0 & 0 & 0 & 30 \\
\hline UFSC & Florianópolis & $\begin{array}{l}\text { 2006/2010: } \\
80 \text { vagas/diurno e } \\
60 \text { vagas/noturno }\end{array}$ & 140 & 140 & 140 & 140 & 140 \\
\hline UFSM & Santa Maria & 2010: 50 vagas/noturno & 0 & 0 & 0 & 0 & 50 \\
\hline
\end{tabular}

Fonte: Elaborado pela autora com base em Andifes (2010).

Na Região Sudeste, a criação de cursos novos é um dos principais mecanismos de expansão, como veremos a seguir, no quadro 5.

Duas informações chamam atenção na Região Sudeste: o curso de Serviço Social, na Universidade Federal dos Vales do Jequitinhonha e Mucuri (Ufvjm), dobrou sua oferta de vagas no período 2006-2010: de 30 para 60 vagas discentes. Já o curso de Serviço Social da Universidade Federal Fluminense (UFF) de Niterói é, certamente, o que oferece o maior número de vagas discentes no país: 220 vagas por ano.

A análise dos dados apresentados pela Andifes demonstra que, das 29 universidades federais que ofertaram vagas para o curso de graduação em Serviço Social no período 2006-2010, 11 instituições têm cursos criados nos anos 2009 e 2010. Diante destes números, recuperamos as questões anteriormente destacadas: a ampliação das vagas discentes corresponde à ampliação de vagas docentes ou expressa um mecanismo de intensificação do trabalho docente e de certificação em larga escala na atualidade? É possível afirmar que este aumento do número de estudantes, sem o aumento igualmente proporcional do número de docentes, está configurando o curso de graduação em Serviço Social como um curso de "educação terciária", desvinculado da pesquisa e da extensão?

Para responder estas questões, indicaremos na próxima seção os dados obtidos, até o momento, sobre o quadro de pessoal docente e de vagas discentes na Universidade Federal Fluminense. O levantamento dos dados dos cursos de Serviço Social das demais universidades federais ainda será realizado na segunda fase da pesquisa, que conta com o apoio financeiro do Edital CNPq/Capes n. 07/2011, de Apoio a Projetos de Pesquisa para o ano de 2012. 
Quadro 5 - Ampliação de vagas discentes nos cursos de graduação em Serviço Social da Região Sudeste no período 2006-2010

\begin{tabular}{|c|c|c|c|c|c|c|c|}
\hline \multirow{2}{*}{\begin{tabular}{c|c} 
Universidade \\
federal
\end{tabular}} & \multirow[t]{2}{*}{ Cidade } & \multirow[t]{2}{*}{ Vagas por ano/turno } & \multicolumn{5}{|c|}{ Total por ano } \\
\hline & & & 2006 & 2007 & 2008 & 2009 & 2010 \\
\hline UFES & Vitória & 2006/2010: 90 vagas/diurno & 90 & 90 & 90 & 90 & 90 \\
\hline \multirow{3}{*}{ UFF } & Campos & $\begin{array}{l}\text { 2006: 100vagas/noturno; } \\
\text { 2007/2009: } 100 \text { vagas/diurno e } \\
\text { 2010: } 110 \text { vagas/diurno }\end{array}$ & 100 & 100 & 100 & 100 & 110 \\
\hline & Niterói & $\begin{array}{l}\text { 2006: } 100 \text { vagas/noturno e } \\
100 \text { vagas/vespertino; } \\
2007: 60 \text { vagas/vespertino e } \\
80 \text { vagas/noturno; } \\
2008: 110 \text { vagas/vespertino e } \\
110 \text { vagas/noturno; } \\
2009: 114 \text { vagas/vespertino e } \\
110 \text { vagas/noturno; } \\
2010: 110 \text { vagas/vespertino e } \\
110 \text { vagas/noturno }\end{array}$ & 200 & 140 & 220 & 224 & 220 \\
\hline & Rio das Ostras & 2007/2010: 70 vagas/noturno & 0 & 70 & 70 & 70 & 70 \\
\hline UFJF & Juiz de Fora & $\begin{array}{l}\text { 2006/2009: } 60 \text { vagas/ diurno; } \\
\text { 2010: } 35 \text { vagas/diurno e } \\
35 \text { vagas/noturno }\end{array}$ & 60 & 60 & 60 & 60 & 70 \\
\hline UFOP & Mariana & $\begin{array}{l}\text { 2009/2010: } 50 \text { vagas/diurno e } 50 \\
\text { vagas/noturno }\end{array}$ & 0 & 0 & 0 & 100 & 100 \\
\hline UFRJ & $\begin{array}{l}\text { Sem informações } \\
\text { no Relatório }\end{array}$ & & & & & & \\
\hline UFTM & Uberaba & 2009/2010: 60 vagas/noturno & 0 & 0 & 0 & 60 & 60 \\
\hline UFU & Uberlândia & 2010: 100 vagas/diurno & 0 & 0 & 0 & 0 & 100 \\
\hline UFVJM & Teófilo Otoni & $\begin{array}{l}\text { 2006: } 30 \text { vagas/noturno; } 2007 / \\
\text { 2010: } 60 \text { vagas/noturno }\end{array}$ & 30 & 60 & 60 & 60 & 60 \\
\hline UNIFESP & Santos & $\begin{array}{l}\text { 2009/2010: } 50 \text { vagas/diurno e } 50 \\
\text { vagas/noturno }\end{array}$ & 0 & 0 & 0 & 100 & 100 \\
\hline UNIRIO & Rio de Janeiro & 2010: 60 vagas/noturno & 0 & 0 & 0 & 0 & 60 \\
\hline
\end{tabular}

Fonte: Elaborado pela autora com base em Andifes (2010).

\section{A certificação em larga escala e a intensificação do trabalho docente na Universidade Federal Fluminense}

A análise do quadro de pessoal docente da UFF será realizada com base nos dados de 1995 a 2010. A recuperação dos dados referentes à década de1990 é importante para a compreensão de que a ampliação de vagas docentes realizada pelo Reuni não respondeu "sequer" as demandas resultantes da expansão de vagas discentes realizada pelas universidades federais na década de 1990 e na primeira década do novo século.

A evolução do quadro de pessoal docente da UFF no referido período (1995-2010) indica o aumento das nomeações de professores no contexto de implantação do Reuni. Este aumento, entretanto, não corresponde às necessidades da universidade para responder a expansão de vagas discentes e de cursos de graduação no período anterior ao Reuni (1995-2006) e, muito menos, no período de implantação do referido Programa.

Segundo Gregório (2011), entre 1995 e 2010, foram nomeados 1.645 professores na UFF. A grandiosidade deste número desaparece quando contabilizamos o número de aposentadorias e de vacâncias geradas por exonerações, falecimentos e posse em outro cargo inacumulável no mesmo período: de 1995 a 2010 foram 
1.111 aposentadorias e 343 vacâncias. Ou seja, no período entre 1995 e 2010, 1.454 professores foram excluídos do quadro de pessoal da UFF. Estes dados demonstram que, no período de 1995 a 2010, ingressaram na UFF 1.645 professores, mas 1.454 professores foram desligados de suas atividades por aposentadoria e vacância, o que significa um saldo positivo de "apenas 191 professores nestes 15 anos analisados".

De 1995 a 2010, segundo o autor, ocorreu um crescimento bastante significativo no número de matrículas nos cursos de graduação da UFF: 15.967, em 1995, e 36.103 em 2010. Se, em 1995, eram 2.572 professores e, em 2010, eram 2.920, registramos um aumento de 13,53\% de professores, enquanto registramos um aumento de $126,11 \%$ no número de matrículas na graduação da UFF, no mesmo período.

No que se refere ao Curso de Serviço Social da Escola de Serviço Social (ESS) da UFF, podemos observar a ampliação do número de vagas oferecidas nos concursos vestibulares de 2006 a 2010.

\section{Quadro 6 - Vagas oferecidas pelo Curso de Serviço Social/ESS/SSN 2006-2010 - concursos vestibulares}

\begin{tabular}{l|c|c|c|c|c|c}
\hline \multirow{3}{*}{ Serviço Social } & $\mathbf{2 0 0 6}$ & $\mathbf{2 0 0 7}$ & $\mathbf{2 0 0 8}$ & $\mathbf{2 0 0 9}$ & $\mathbf{2 0 1 0}$ \\
\cline { 2 - 7 } & 200 & 140 & 220 & 224 & 220 \\
\hline
\end{tabular}

Fonte: Elaborado pela autora, com base em Gregório (2011).

Além da expansão das vagas discentes oferecidas pela ESS/UFF na graduação, e do trabalho acadêmico resultante desta ampliação (preparação de aulas; elaboração e correção de trabalhos e provas; orientações de monografias; supervisão acadêmica de estágio; orientação de monitores, de bolsistas de pesquisa e de extensão), outras atividades devem ser consideradas na análise do trabalho docente e da formação profissional realizado na ESS/UFF. Atividades de pesquisa e de extensão; político-administrativas e de representação em comissões e em cargos na universidade e fora da universidade; participação em eventos científicos e nos dois Programas de Pós-Graduação/PPG da unidade de ensino (PPG em Serviço Social e Desenvolvimento Regional e PPG em Política Social) são constitutivas da carga horária docente.

Apesar da ampliação das tarefas político-acadêmicas dos docentes e do número de vagas discentes na ESS/UFF, dados da pesquisa realizada por Gregório (2011) indicam que o crescimento do número de professores na unidade de ensino ficou praticamente inalterado.

Quadro 7 - Quadro de pessoal docente da Escola de Serviço Social da UFF por ano - 2006-2010

\begin{tabular}{|c|c|c|c|}
\hline Ano & Professores efetivos & Professores substitutos & Total \\
\hline $\mathbf{2 0 0 6}$ & 33 & 10 & 43 \\
\hline $\mathbf{2 0 0 7}$ & 34 & 08 & 42 \\
\hline $\mathbf{2 0 0 8}$ & 34 & 09 & 43 \\
\hline $\mathbf{2 0 0 9}$ & 37 & 11 & 46 \\
\hline $\mathbf{2 0 1 0}$ & 38 & 08 & 46 \\
\hline
\end{tabular}

Fonte: Elaborado pela autora, com base nos dados de Gregório (2011).

Atualmente, o Curso de Serviço Social da ESS/UFF é o maior curso público/federal, em oferta de vagas discentes, de Serviço Social do país e o terceiro curso da UFF com maior oferta de vagas no vestibular: 220 vagas (110 para o curso vespertino e 110 vagas para o curso noturno). Em 2011, o Curso de Serviço Social/ESS dispunha de 39 docentes efetivos, sendo 35 em regime de trabalho de Dedicação Exclusiva (DE) e quatro professores em regime de 20 horas. Neste mesmo período, eram 1.086 alunos matriculados, perfa- 
zendo um total de um professor para cada 34,38 alunos. Média muito superior ao exigido pelo contrato de gestão/Reuni que é de 1/18 (UFF, 2011).

A ampliação de vagas discentes sem a contrapartida de vagas docentes em número suficiente para assumir as atividades na graduação, na pós-graduação, na pesquisa, na extensão, nas orientações e nas tarefas administrativas, impostas pela universidade e pelos órgãos de fomento, indica a dificuldade para a efetivação da indissociabilidade ensino-pesquisa-extensão. $\mathrm{O}$ docente, neste quadro de expansão precarizada, assume turmas lotadas; está sobrecarregado com excesso de disciplinas, supervisão de estágio curricular e orientação de monografias e, ainda, com as tarefas administrativas que fazem parte do cotidiano da universidade. Parte significativa dos docentes acaba desvinculada da pesquisa, dos programas de pós-graduação e da produção crítica e criativa do conhecimento, especialmente se for contratado como professor substituto ou temporário. A ampliação deste tipo de contratação (por tempo determinado, mal remunerado, desprovido de direitos trabalhistas, centrado no ensino de graduação) é o resultado do corte de $\mathrm{R} \$ 50$ bilhões no Orçamento Geral da União (OGU), realizado pelo Governo Federal em 2011; do corte de $\mathrm{R} \$ 55$ bilhões no OGU realizado pelo Governo Federal em 2012; da Medida Provisória 525/11 e da Portaria do MEC n. 196 de 24/02/2011, publicada no Diário Oficial da União em 25/02/2011, liberando a contratação de professores substitutos/temporários para que as universidades federais cumprissem as metas do Reuni nos exercícios 2011 e 2012.

\section{Conclusão}

As análises dos resultados parciais da pesquisa demonstram como o novo padrão de gestão do trabalho e do Estado no contexto da mundialização financeira resultam na intensificação do trabalho, particularmente em um país capitalista dependente como o Brasil. Neste quadro analítico é que devemos inscrever a intensificação do trabalho docente nos marcos da reforma neoliberal do Estado e da educação superior brasileira.

\section{A ampliação de vagas discentes} sem a contrapartida de vagas docentes em número suficiente para assumir as atividades na graduação, na pós-graduação, na pesquisa, na extensão, nas orientações e nas tarefas administrativas, impostas pela universidade e pelos órgãos de fomento, indica a dificuldade para a efetivação da indissociabilidade ensinopesquisa-extensão.

Neste contexto, a certificação em larga escala, com ênfase no ensino de graduação e a intensificação do trabalho docente, constituem duas faces da política de expansão operada pelo Reuni nas universidades federais. Os estudos e as pesquisas que realizamos estão demonstrando que o número de vagas docentes "não" corresponde às necessidades das universidades federais para responder à expansão de vagas discentes realizada no período anterior ao Reuni (anos de 1990 até 2006) e, muito menos, no período de implantação do referido Programa.

Cabe ressaltar que o Andes-SN já sinalizava, desde a divulgação do Reuni, o significado político e acadêmico do referido Programa. Em nota lançada em agosto de 2007, o Sindicato Nacional alertava para o fato de que a ampliação da oferta de matrículas, com o aumento de, no máximo, $20 \%$ dos recursos financeiros, indicava "o caminho da transformação do conjunto de IFES em escolas de terceiro grau, sem reais possibilidades de honrarem o tripé universitário, que conjuga pesquisa, ensino e extensão" (ANDES-SN, 2007, p. 2).

Consideramos que a expansão das universidades federais, com qualidade, só pode ser garantida a partir de um conjunto de ações. Primeiramente, a ampliação da alocação de verba pública para a educação pública. A análise da relação entre os valores do Orçamento Geral da União alocados para o pagamento da dívida pública e o financiamento das áreas sociais demonstra qual tem sido a prioridade dos diferentes governos. Em 2002, o Governo Federal destinou R \$ 120 bilhões do orçamento para o pagamento do serviço da dívida e R 71 bilhões com todas as áreas sociais (Segurança Pública, Assistência Social, Saúde, Educação, Cultura, Urbanismo, Habitação, Saneamento, Gestão Ambiental, Ciência e Tecnologia, Agricultura, Organização Agrária e Energia). Em 2011, 45,05\% do orçamento foi destinado aos juros e amortizações da dívida, enquanto apenas 2,99\% foram destinados à educação, segundo os dados da Auditoria Cidadã da Dívida. Reverter este quadro é tarefa urgente quando projetamos a ampliação do acesso com qualidade à educação superior pública. 
Outra ação prioritária seria o fortalecimento da universidade pública através da alocação de verba pública exclusivamente para a educação superior pública, o que significa a eliminação de toda forma de destinação orçamentária ou isenção/renúncia fiscal (Financiamento ao Estudante do Ensino Superior (FIES), Programa Universidade para Todos (ProUni)) para os empresários da educação superior e o aumento do investimento público direto na educação pública.

Nos últimos anos, encontramos dois problemas no que se refere ao financiamento: a) os valores destinados à educação são ínfimos, para toda a área da educação, incluindo educação infantil, básica, ensino fundamental, médio e superior, o Brasil aplicou 4,7\% do Produto Interno Bruto (PIB) em 2000 e 5,8\% do PIB em 2010 e, b) o conceito de investimento público total em relação ao PIB inclui a transferência de verba pública para o setor privado educacional, fortalecendo a ação dos empresários da educação. Destes valores, apenas $0,9 \%$ do PIB foi alocado para a educação superior desde o ano 2000, com pequenas alterações em 2002 $(1,0 \%)$ e nos anos 2004, 2006 e 2007, quando o valor caiu para $0,8 \%$ do PIB, conforme os dados do Instituto Nacional de Estudos e Pesquisas Educacionais Anísio Teixeira (INEP).

Um quadro que não deverá ser alterado, pois a Comissão Especial da Câmara dos Deputados aprovou, em 26/06/2012, o Plano Nacional de Educação (Projeto de Lei - PL 8035/2010), prevendo que "somente no ano 2023" os governos federal, estaduais e municipais deverão aplicar, em educação, recursos equivalentes a $10 \%$ do PIB. O PL também prevê que tal percentual suba dos atuais 5\% para 7\% do PIB em 2017. Para virar lei, o Plano Nacional de Educação ainda precisa ser aprovado pelo Senado e ser sancionado, sem vetos, pela presidenta Dilma Rousseff.

Além dessas ações, a oferta da educação superior pública federal para as várias regiões e cidades, por meio de uma política de interiorização, deverá ser realizada de forma a assegurar condições de trabalho e de formação. Assim, a garantia da oferta da educação pública com infraestrutura e o número suficiente de docentes e técnico-administrativos para o desenvolvimento das atividades de ensino, pesquisa e extensão, eliminarão qualquer possibilidade de uma formação diferenciada e hierarquizada, que concentra nas sedes das universidades federais os programas de pós-graduação, a pesquisa e os laboratórios, reduzindo as universidades e as unidades de ensino localizadas no interior dos estados a instituições de "educação terciária", conforme noção elaborada e difundida pelo Banco Mundial. Seria necessária, também, a criação de políticas de valorização do trabalho docente por intermédio de condições dignas de trabalho, de carreira e de remuneração pautadas na isonomia e, ainda, de estímulo à atividade crítica e criativa de produção e socialização do conhecimento que atenda às lutas e demandas históricas dos trabalhadores.

No atual contexto marcado pela expansão precarizada nas universidades federais, o Curso de Serviço Social foi identificado no Relatório de Acompanhamento do Reuni, elaborado pela Andifes (2010), como o segundo curso com maior expansão de vagas discentes nas universidades federais, no período 2006/2010.

A compreensão do processo de expansão da educação superior e, especialmente, da relação entre vagas discentes e vagas docentes é, portanto, uma necessidade urgente, pois esta relação indica como ocorre a intensificação do trabalho docente e a certificação em larga escala, com ênfase no ensino de graduação, particularmente nos cursos de Serviço Social. Duas faces da política de expansão operada pelo Reuni que apresentam um conjunto de desafios para o projeto de formação profissional construído pela Abepss, Enesso e Cfess, que tem como centralidade a indissociabilidade entre ensino, pesquisa e extensão e a capacitação política, teórico-metodológica e técnico-operativa dos futuros assistentes sociais.

\section{Referências}

ANDES-SN-Sindicato Nacional dos Docentes das Instituições de Ensino Superior. Dinheiro do Reuni já acabou, diz ministro. 2009. Disponível em: 〈http://www.adufpi.org.br/arquivos/dinheirodoreuniacabou.pdf〉. Acesso em: 2 maio 2011.

. Nota (preliminar) da diretoria do Andes-SN. O Programa Reuni na prática. (O que revelam as diretrizes do Reuni). Disponível em: <http://www.adufrgs.org.br/Biblioteca\%20de\%20Documentos/REUNI/Nota\%20Preliminar\%20da\%20Andes.pdf>. Acesso em: 2 maio 2011.

ANDIFES. Relatório de Acompanhamento do Programa de Apoio a Planos de Reestruturação e Expansão - Reuni. Brasília: Andifes, jan. 2010 .

ANTUNES. R.; ALVES, G. As mutações no mundo do trabalho na era da mundialização do capital. 2004. Disponível em: <http:// www.praxis.ufsc.br:8080/xmlui/bitstream/handle/praxis/122/As\%20muta\%C3\%A7\%C3\%B5es\%20no\%20mundo\%20do\%20trabalho $\% 2$ 0na\%20era\%20da\%20mundializa\%C3\%A7\%C3\%A3o\%20do\%20capital.pdf?sequence=1>. Acesso em: 7 jul. 2010.

BANCO MUNDIAL. Construir sociedades de conocimiento: nuevos desafíos para la Educación Terciaria. 2002. Disponível em: <http://siteresources.worldbank.org/EDUCATION/Resources/278200-1099079877269/547664-1099079956815/CKS-spanish.pdf〉. Acesso em: 1 jul. 2012. 
BARRETO, R. G.; LEHER, R. Do discurso e das condicionalidades do Banco Mundial, a educação superior “emerge” terciária. Revista Brasileira de Educação, Rio de Janeiro, v. 13, n. 39, p. 423-436, 2008.

BOSI, A. de P. Precarização do trabalho docente: novas e velhas formas da dominação capitalista (1980-2005). Universidade e Sociedade, Brasília: Andes-SN, n. 38, p. 43-59, 2006.

. A precarização do trabalho docente nas instituições de ensino superior do Brasil nos últimos 25 anos. Educação \& Sociedade, Campinas, SP, v. 28, n. 101, p. 1503-1423, 2007. Disponível em: 〈http://www.scielo.br/pdf/es/v28n101/a1228101.pdf>. Acesso em: 7 jul. 2010.

. Avaliação como forma atualizada de dominação e intensificação do trabalho docente (1980-2005). Movimento em debate, Campinas, SP: Adunicamp, ano 2, n. 3, p. 26-37, maio 2009. Disponível em: <http://www.adusp.org.br/campanhas/produtivismo/ movimento.pdf>. Acesso em: 7 jul. 2010.

BRASIL. Decreto n. 6.096, de 24 de abril de 2007. Institui o Programa de Apoio a Planos de Reestruturação e Expansão das Universidades Federais - Reuni. Disponível em: <http://www.planalto.gov.br/ccivil_03/_ato2007-2010/2007/decreto/d6096.htm>.Acesso em: 1 jul. 2012.

GREGÓRIO, J. R. B. de. Política de pessoal docente do governo Lula: uma análise do Reuni na UFF e seus desdobramentos. 2011.259 f. Dissertação (Mestrado em Educação) - Programa de Pós-Graduação em Educação, Universidade Federal Fluminense. Niterói: UFF, 2011. LIMA, K. Trabalho docente e formação profissional nas universidades federais. Revista de Políticas Públicas, UFMA: São Luís, MA, n. esp., p. 313-321, 2010.

. O Banco Mundial e a educação superior brasileira na primeira década do novo século. Revista Katálysis, Florianópolis: Edufsc, v. 14, n. 1, p. 86-94, jan./jun. 2011. Disponível em: 〈http://www.scielo.br/pdf/rk/v14n1/v14n1a10.pdf〉. Acesso em: 1 jul. 2012.

. Precarização e intensificação: as novas faces do trabalho docente. Universidade e Sociedade, Brasília: Andes-SN, ano XX, n. 47, p. 149-158, 2011a.

SGUISSARDI, V.; SILVA JÚNIOR, J. dos R. O trabalho intensificado nas federais: pós-graduação e produtivismo acadêmico. São Paulo: Xamã, 2009.

UFF-Universidade Federal Fluminense. Documentos docentes. Niterói: Rio de Janeiro, 2011. Disponível em: <http://www.ess.uff.br/ images/stories/Download_Estgio/Download_Coordenao/2_-_DOCUMENTO_DOCENTES_ESS_UFF.pdf>.Acesso em: 1 jul. 2012.

\section{Nota}

1 Para aprofundar a análise do processo de intensificação do trabalho docente nas universidades federais, consultar Sguissardi e Silva Júnior (2009) e Bosi, (2006, 2007, 2009).

\section{Kátia Regina de Souza Lima}

katiaslima@globo.com

Doutora em Educação pela Universidade Federal Fluminense (UFF)

Professora da Escola de Serviço Social e do Programa de Pós-Graduação em Educação da UFF

\section{UFF - Escola de Serviço Social}

Campus do Gragoatá, Blocos D e E

São Domingos

Niterói - Rio de Janeiro - Brasil

CEP: 24210-350 